\title{
Clinical and laboratory predictors of survival for pediatric patients on non-postcardiotomy extracorporeal membrane oxygenation (ECMO)
}

\author{
Güntülü Ş $\mathrm{k}^{1 \oplus}$, Asuman Demirbuğa ${ }^{1}$, Agageldi Annayev ${ }^{1}$, Bahar Temur², \\ Selim Aydın², Halil İbrahim Demir³ ${ }^{3}$ Ersin Erek², Agop Çıtak ${ }^{1}$ \\ Departments of ${ }^{1}$ Pediatric Intensive Care, ${ }^{2}$ Cardiovascular Surgery and ${ }^{3}$ Pediatric Cardiology, Acrbadem Mehmet Ali Aydinlar \\ University, İstanbul, Turkey.
}

\begin{abstract}
Extracorporeal membrane oxygenation (ECMO) is used in pediatric patients with severe cardiopulmonary failure who do not respond to conventional therapy; only a few studies have been conducted in Turkey. We present the experience of pediatric ECMO with the aim of showing factors affecting mortality. We retrospectively reviewed our ECMO database to identify patients who received ECMO from October 2015 to March 2018. Our population comprised 30 pediatric patients. The mean patient age was $41.31 \pm 53.35$ months and $17(56.7 \%)$ patients were male. The median duration of ECMO support was $8.9(6.6-10.8)$ days. The rates of successful ECMO weaning and survival to discharge were $70.0 \%(\mathrm{n}=21)$ and $66.7 \%(\mathrm{n}=20)$, respectively. Indications for ECMO were respiratory failure $(40.0 \%)$, cardiac failure $(33.3 \%)$, and sepsis $(26.7 \%)$. We found that pre-cannulation values of $\mathrm{pH}(\mathrm{p}=0.034)$, leukocytes $(\mathrm{p}=0.029)$, C-reactive protein $(\mathrm{p}=0.045)$, creatinine $(\mathrm{p}=0.047)$, chloride $(\mathrm{p}=0.001)$ and post-cannulation $\mathrm{pH}(\mathrm{p}=0.0001)$, bicarbonate $(\mathrm{p}=0.014)$, lactate $(\mathrm{p}=0.002)$, chloride $(\mathrm{p}=0.0001)$ were associated with mortality. The results showed that preexisting sepsis and renal conditions contributed to poor outcomes. Indications, ECMO onset time, and pre- and post-cannulation laboratory values such as leukocytes, CRP, creatinine, bicarbonate, lactate, and chloride are factors that affect outcomes.
\end{abstract}

Key words: extracorporeal membrane oxygenation, pediatric intensive care, chloride, lactate.

Extracorporeal membrane oxygenation (ECMO) is an effective treatment method performed in patients with severe cardiopulmonary failure who are resistant to medical treatment, and provides temporary cardiopulmonary support. This technique involves oxygenation of the blood outside the body, thereby obviating the need for gas exchange in the lungs, and it can also aid cardiovascular circulation if necessary.

The first successful ECMO treatment was performed in an infant with congenital heart defects undergoing cardiac surgery in 1970 by Baffes et al. ${ }^{1}$

Güntülü Şık

drguntulu@hotmail.com

Received 20th December 2018; revised 6th March 2019,

15th May 2019, 1st August 2019; accepted 2nd August 2019
In 1975, Bartlett et al. ${ }^{2}$ reported the first successful use of ECMO in neonates with severe respiratory distress. Since then, ECMO has increased gradually in pediatric cardiacrespiratory support and showed certain benefits. Currently, ECMO is one of the most important treatment modalities worldwide for cardiac and pulmonary failure in children.

In the present study, we studied children who received venoarterial (VA) and venovenous (VV) ECMO support in a pediatric intensive care unit. We tried to describe the current status of ECMO in children for both cardiac and pulmonary support and the risk factors associated with their outcomes. 


\section{Material and Methods}

\section{Study population}

All patients $(n=30)$ aged younger than 18 years who received VV or VA-ECMO support in the pediatric intensive care unit (PICU) of Acibadem Mehmet Ali Aydinlar University School of Medicine between October 2015 and March 2018 were retrospectively evaluated. Ethics board approval of Acibadem Mehmet Ali Aydınlar University was granted (31.05.2018, 2018-8/8).

\section{ECMO setting}

Maquet or Medos ECMO systems were used. Cannulation was performed through cardiovascular surgery. The cannula size was selected in accordance with the age, height, and weight of the patient. The right internal jugular vein-femoral vein was used in all patients who had VV-ECMO support, and the right common carotid artery-right internal jugular vein was used in 18 patients who received VA-ECMO. The right common carotid artery-left femoral vein was used in 1 patient, and the femoral artery-femoral vein was used in 5 patients.

A perfusionist is present 24 hours per day in our hospital. Before cannulation, patients received heparin at a loading dose of $50 \mathrm{U} / \mathrm{kg}$. During ECMO, heparin infusion continued by following the activated clotting time (ACT). The target was to keep ACT between 170-220 sec, hemoglobin levels $>10 \mathrm{~g} / \mathrm{dl}$, and platelet count $>100.000 / \mathrm{mm}^{3}$

Adjunct flow volume was adjusted according to the hemodynamic insides and was maintained at $100-150 \mathrm{ml} / \mathrm{kg} / \mathrm{min}$ to keep venous oxygen saturation at $>70 \%$ for patients with VAECMO. Patients were evaluated through daily echocardiographic and chest X-rays. All patients received pressure-controlled synchronized intermittent mechanical ventilation. Throughout ECMO, the following parameters were kept between these values: fractional inspired oxygen $\left(\mathrm{FiO}_{2}\right)$ 30-45\%, frequency 10-18/min, positive end-expiratory pressure (PEEP) 8-12 $\mathrm{cm} \mathrm{H}_{2} \mathrm{O}$.

The indications were divided into three groups as cardiac failure, respiratory failure, and sepsis. Ten patients were diagnosed as having cardiac failure [congenital heart disease (CHD), myocarditis, cardiomyopathy (CMP), or intractable arrhythmia], 12 patients had hypoxemic respiratory failure (bacterial pneumonia, pneumonia and acute respiratory distress syndrome) and 8 patients had sepsis.

VA-ECMO indications for patients were evidence of inadequate end organ perfusion and oxygen delivery resulting from inadequate systemic cardiac output;

- Hypotension despite maximum doses of two inotropic or vasopressor medications,

- Low cardiac output with evidence of end organ malperfusion despite medical support as described above: persistent oliguria, diminished peripheral pulses.

- Low cardiac output with mixed venous, or superior caval central venous (for single ventricle patients) oxygen saturation $<50 \%$ despite maximal medical support.

- Low cardiac output with persistent lactate $>4.0 \mathrm{mmol} / \mathrm{L}$ and persistent upward trend despite optimization of volume status and maximal medical management.

Patients who underwent ECMO for hypoxemic respiratory failure had an oxygenation index (OI) $>16$ or oxygenation saturation index (OSI) $>12.3$, despite the use of lung protective mechanical ventilation strategy, low tidal volume ventilation $(5-8 \mathrm{ml} / \mathrm{kg})$, alveolar recruitment maneuvers with high PEEP, prone positioning, high-frequency oscillatory ventilation (HFOV) and neuromuscular blockage agents.

Oxygenation index (OI) was defined as $\left(\left[\mathrm{FiO}_{2} \times\right.\right.$ mean airway pressure $\left.(\mathrm{Paw}) \times 100] / \mathrm{PaO}_{2}\right)$ and oxygenation saturation index $(\mathrm{OSI})\left(\left[\mathrm{FiO}_{2} \times \mathrm{Paw}\right.\right.$ $\left.\times 100 \mathrm{~J} / \mathrm{SpO}_{2}\right)$. 


\section{Definitions for variables}

Pre-cannulation, we recorded the following information: age, sex, weight, pediatric risk of mortality score (PRISM), pediatric logistic organ dysfunction score (PELOD), time from PICU admission to cannulation, the pre-ECMO vasoactive-inotropic score (VIS). Inotropic score (IS) = dopamine dose $(\mathrm{mcg} / \mathrm{kg} / \mathrm{min})+$ dobutamine dose $(\mathrm{mcg} / \mathrm{kg} / \mathrm{min})+$ epinephrine dose $(\mathrm{mcg} / \mathrm{kg} / \mathrm{min}) \times 100$. Vasoactive-inotropic score $($ VIS $)=$ IS $+10 \times$ milrinone dose $(\mathrm{mcg} / \mathrm{kg} /$ $\min )+10,000 \times$ vasopressin dose (units $/ \mathrm{kg} / \mathrm{min}$ ) $+100 \times$ norepinephrine dose $(\mathrm{mcg} / \mathrm{kg} / \mathrm{min})$. The pre- and post-cannulation heart rate, systolic and diastolic pressure levels, and laboratory variables were recorded. The routinely measured laboratory parameters were white blood cell count, hemoglobin, platelets, prothrombin time, activated partial thromboplastin time, urea, creatinine, serum glutamic oxaloacetic transaminase (SGOT), serum glutamic pyruvic transaminase (SGPT), albumin, chloride, lactate dehydrogenase (LDH), C-reactive protein (CRP), $\mathrm{pH}$, partial pressure of $\mathrm{O}_{2}$ in the arterial blood $\left(\mathrm{paO}_{2}\right)$, partial pressure of $\mathrm{CO}_{2}$ in the arterial blood $\left(\mathrm{pCO}_{2}\right)$, sodium bicarbonate $\left(\mathrm{HCO}_{3}\right)$, and lactate.

Overall outcomes including the successful weaning rate and the survival to discharge rate were calculated.

Complications due to ECMO were grouped according to the The Extracorporeal Life Support Organization (ELSO) registry in the following categories: 1) metabolic, 2) cardiovascular, 3) infectious, 4) renal, 5) hemorrhagic, 6) neurologic, 7) pulmonary, and 8) mechanical.

\section{Weaning}

Cannula position, cardiac functions, effusions and air leakage were evaluated through daily bedside echocardiography and chest radiography. The patients were prepared for weaning when cardiac and pulmonary function improved. During the weaning period, patients required low-dose catecholamine and the mechanical ventilation parameters were increased.

\section{Statistical analysis}

The statistical analysis was performed using the Number Cruncher Statistical System (NCSS) 2007 Statistical Software package program (Utah, USA). Independent t-test was used in the comparison of paired variables with normal distribution, and Mann-Whitney U test was used in the comparison of paired groups with variables with non-normal distribution. Chi-square test was used in the comparison of qualitative data in addition to descriptive statistical methods (mean, standard deviation) in the evaluation of the data. Logistic regression analysis was used to identify factors that affected patient loss. The results were evaluated with a significance value of $\mathrm{p}<0.05$.

\section{Results}

A total of 30 patients comprising 13 girls (43.3\%) and 17 boys $(56.7 \%)$ were included in the study between October 2015 and March 2018. The demographic data of the patients are shown in Table I and Table II.

The mean age was $41.31 \pm 53.35$ months. The mean weight of all patients was $11.96 \pm 8.97 \mathrm{~kg}$; $12.65 \pm 9.92 \mathrm{~kg}$ in the survivors, and $10.55 \pm 7.01 \mathrm{~kg}$ in the non-survivors. In addition, $80 \%$ (24 of 30) of the patients were on VA-ECMO, whereas $20 \%$ (6 of 30) were on VV-ECMO. Altogether, 70\% (21 of 30) of the patients were successfully weaned from ECMO and the survival to discharge rate for all patients was $66.7 \%$ (20 of 30). The survival rate in both groups receiving VA (16/24) and VV $(4 / 6)$ ECMO was $66.7 \%$. Survival frequency was not significantly affected by ECMO support type, sex, and weight.

ECMO was performed due to cardiac causes in 10 patients, respiratory causes in 12 patients, and catecholamine-resistant sepsis in 8 patients. The most common ECMO indication was hypoxemic respiratory failure. The most frequent cardiac cause was acute myocarditis. 
Table I. Demographic data of patients who received ECMO support.

\begin{tabular}{lccc}
\hline Features & Survivors $(\mathrm{n}=20)$ & Non-survivors $(\mathrm{n}=10)$ & $\mathrm{p}$ \\
\hline Age, months & $38.17 \pm 46.64$ & $47.61 \pm 67.53$ & $0.757^{*}$ \\
Weight, kg & $12.65 \pm 9.92$ & $10.55 \pm 7.01$ & $0.816^{*}$ \\
Timing of ECMO initiation, hours & $3.85(2.88-18.75)$ & $31.3(5.05-53.35)$ & 0.012 \\
Vasoactive inotropic score & $61(41.25-178.75)$ & $157(112.38-165.75)$ & 0.115 \\
CRP, $\mathrm{mg} / \mathrm{dl}$ & $4.13(1.025-7.85)$ & $7.73(5.68-19.71)$ & $0.045^{*}$ \\
Procalcitonin, $\mathrm{ng} / \mathrm{ml}$ & $8.59(2.163-24.275)$ & $9.09(2.515-102.85)$ & 0.697 \\
Albumin, g/dl & $2.51 \pm 0.79$ & $2.1 \pm 0.8$ & $0.325^{*}$ \\
Troponin-I, ng/ml & $2.8(0.3855-13.966)$ & $3.65(0.938-27.65)$ & 0.739 \\
Creatine kinase-MB, IU/ml & $84(48.5-236)$ & $183.5(82.33-533)$ & 0.279 \\
LVEF & $27(18.75-50)$ & $47.5(18-54.25)$ & 0.441 \\
PRISM score & $23(15-30)$ & $24(19-31)$ & 0.689 \\
PELOD score & $21(12-32)$ & $21(20-28.75)$ & 0.851 \\
\hline
\end{tabular}

*Independent t-test (mean $\pm \mathrm{SD})$, ŁMann-Whitney U test (median, IQR), +Chi-square test

ECMO: extracorporeal membrane oxygenation, LVEF: left ventricular ejection fraction, PRISM: pediatric risk of mortality score, PELOD: pediatric logistic organ dysfunction.

Table II. Outcomes of patients who received ECMO support.

\begin{tabular}{lccc}
\hline Parameters & $\begin{array}{c}\text { All patients } \\
(\mathrm{n}=30)\end{array}$ & $\begin{array}{c}\text { VA-ECMO } \\
(\mathrm{n}=24)\end{array}$ & $\begin{array}{c}\text { VV-ECMO } \\
(\mathrm{n}=6)\end{array}$ \\
\hline Median ECMO time, days & $8.9(6.6-10.8)$ & $9.35(6.8-12.2)$ & $7.3(6.1-9.4)$ \\
Weaning, n (\%) & $21(70 \%)$ & $17(70.8 \%)$ & $4(66.7 \%)$ \\
Survivor, n $(\%)$ & $20(66.7 \%)$ & $16(66.7 \%)$ & $4(66.7 \%)$ \\
CPR before ECMO & $8(26.7 \%)$ & $6(25.0 \%)$ & $2(33.3 \%)$ \\
\hline
\end{tabular}

CPR: cardiopulmonary resuscitation, ECMO: extracorporeal membrane oxygenation, VA: venoarterial, VV: venovenous

Table III. Underlying diagnoses and outcomes of extracorporeal membrane oxygenation.

\begin{tabular}{lccc}
\hline Diagnosis & Total, $\mathrm{n}$ & Survivors, $\mathrm{n}$ & $\%$ \\
\hline Cardiac reasons & 3 & 2 & 66.7 \\
$\quad$ Congenital heart disease & 5 & 4 & 80.0 \\
$\quad$ Acute myocarditis & 1 & 1 & 100.0 \\
$\quad$ Resistant Arrhythmia & 1 & 1 & 100.0 \\
$\quad$ Cardiomyopathy & & & 83.3 \\
Respiratory causes & 12 & & \\
$\quad$ Hypoxemic respiratory failure & & 2 & 25.0 \\
Other & 8 & & \\
$\quad$ Sepsis & & & \\
\hline
\end{tabular}

Three patients were diagnosed as having congenital heart disease. The patient with transposition of great arteries diagnosis underwent reconstruction of the arcus aorta with arterial switch operation, due to arcus aorta hypoplasia. 18 months after operation, venoarterial ECMO was performed with the diagnosis of heart failure due to aortic recoarctation. The patient was operated under ECMO support, underwent coarctation repair. He weaned from ECMO successfully. The first patient with total anomalous pulmonary venous 
drainage (TAPVD) diagnosis, pulmonary vein stenosis and heart failure developed 6 months after total correction. ECMO was the bridge for transplantation, but he died due to multiorgan failure during ECMO support. The second patient with TAPVD diagnosis was operated on 8 months ago. Venoarterial ECMO was performed with the diagnosis of sepsis, pulmonary hypertension and heart failure. She weaned from ECMO after 8 days support.

Sepsis, eventually superimposed with cardiac or respiratory conditions, was the indication for ECMO in approximately $26.7 \%(n=8)$ of cases. The highest mortality was detected in patients who were performed ECMO due to sepsis; 6 patients died, and 5 patients in this group were bone marrow transplant patients. The indications of ECMO are shown in Table III.

The median ECMO period was 8.9 (6.6-10.8) days; 9.35 (6.8-12.2) days for VA-ECMO and 7.3 (6.1-9.4) days for VV-ECMO. Cardiopulmonary resuscitation (CPR) was performed for 8 patients before starting ECMO. CPR was continued during cannulation in 4 patients (E-CPR); 2 of these 4 patients survived, and 2 died. Continuous renal replacement treatment was performed over the ECMO set in 25 patients.

Hemorrhagic complications were detected in $5(16.7 \%)$ patients, neurologic complications were observed in $2(6.7 \%)$ patients, and 3 $(10.0 \%)$ patients had mechanical complications. Hemorrhagic complications were surgical site bleeding, nasopharyngeal bleeding, hematuria, and hemothorax. Neurologic complications $(n=2)$ were intracranial bleeding and intracranial infarct; decompressive bone surgery was performed to the infarct due to secondary bleeding and due to intracranial pressure increase syndrome. The patient was discharged with mild neurologic sequela after bone correction surgery. Mechanical complications were cannula perforation and position disorder, which required decannulation and recannulation. Recannulation was performed with no need for the set to be changed in any patients.
Survivorandnon-survivorpatientsarecompared in Table I. The vasoactive inotropic score was 157 in non-survivor patients at admission to the PICU, and the vasoactive inotropic score was 61 in survivors; however, there was no statistical difference in the comparison of vasoactive VIS, left ventricular ejection fraction (LVEF), PRISM, PELOD, procalcitonin, troponin I, and creatine kinase-MB (CK-MB) values between the two groups. CRP levels were found to be higher in non-survivor patients $(\mathrm{p}=0.045)$. Early ECMO initiation was associated with improved survival when compared with late ECMO $(\mathrm{p}=0.012)$.

Table IV shows the vital signs and laboratory values for survivors and non-survivor patients on ECMO pre-cannulation and one day after cannulation. Our analysis shows no statistically significant difference between two groups for the following values at pre-cannulation: heart rate, systolic and diastolic blood pressure, arterial oxygen saturation, $\mathrm{pCO}_{2^{\prime}} \mathrm{paO}_{2^{\prime}}$ sodium bicarbonate, lactate, hemoglobin, platelet count, urea, albumin, and LDH. On the other hand, white blood cells $(\mathrm{WBC})(\mathrm{p}=0.029)$ and $\mathrm{C}$-reactive protein $(C R P)(p=0.045)$ and laboratory values associated with kidney function $[\mathrm{pH}(\mathrm{p}=0.034)$, creatinine $(p=0.047)$, and chloride $(p=0.001)]$ were statistically significantly different between both groups precannulation.

Furthermore, $\mathrm{pH}(\mathrm{p}=0.001), \mathrm{pCO}_{2} \quad(\mathrm{p}=0.043)$, $\mathrm{HCO}_{3} \quad(\mathrm{p}=0.014)$, lactate $(\mathrm{p}=0.002), \quad \mathrm{LDH}$ $(\mathrm{p}=0.039)$, and chloride $(\mathrm{p}=0.001)$ values were statistically different between the survivors and non-survivors on day-1 after cannulation.

In addition, the comparison of data of precannulation and day-1 showed that the improvement in heart rate beat $(p=0.0001)$, systolic blood pressure $(\mathrm{p}=0.013)$, diastolic blood pressure $(\mathrm{p}=0.001)$, arterial oxygen saturation $(\mathrm{p}=0.0001), \mathrm{pH} \quad(\mathrm{p}=0.0001), \mathrm{pCO}_{2} \quad(\mathrm{p}=0.002)$, $\mathrm{paO}_{2}(\mathrm{p}=0.0001), \mathrm{HCO}_{3}(\mathrm{p}=0.007)$, and lactate $(\mathrm{p}=0.002)$ levels were statistically significant in the survivors compared with the non-survivor patients. 
Table IV. The vital signs and laboratory values for survivor and non-survivor patients on ECMO.

\begin{tabular}{|c|c|c|c|c|}
\hline \multirow{4}{*}{$\begin{array}{l}\text { Parameters } \\
\text { Heart rate }\end{array}$} & & Survivors $(\mathrm{n}=20)$ & Non-survivor $(\mathrm{n}=10)$ & $\mathrm{p}$ \\
\hline & Initial & $166.71 \pm 37.45$ & $163.25 \pm 33.91$ & $0.827^{*}$ \\
\hline & Day-1 & $121.53 \pm 19.52$ & $129 \pm 32.2$ & $0.477^{*}$ \\
\hline & pt & 0.0001 & 0.005 & \\
\hline \multirow[t]{3}{*}{ Systolic BP } & Initial & $76.35 \pm 19.65$ & $79.75 \pm 23.85$ & $0.710^{*}$ \\
\hline & Day-1 & $89.94 \pm 13.8$ & $81.63 \pm 29.74$ & $0.343^{*}$ \\
\hline & p + & 0.013 & 0.877 & \\
\hline \multirow[t]{3}{*}{ Diastolic BP } & Initial & $43.18 \pm 10.82$ & $50.63 \pm 18.17$ & $0.210^{*}$ \\
\hline & Day-1 & $55.53 \pm 8.78$ & $50.63 \pm 22.78$ & $0.440^{*}$ \\
\hline & pt & 0.001 & 0.999 & \\
\hline \multirow[t]{3}{*}{$\begin{array}{l}\text { Arterial oxygen } \\
\text { saturation }\end{array}$} & Initial & $71.71 \pm 18.26$ & $81.38 \pm 11.25$ & $0.183^{*}$ \\
\hline & Day-1 & $92.94 \pm 2.93$ & $95 \pm 3.85$ & $0.157^{*}$ \\
\hline & pt & 0.0001 & 0.017 & \\
\hline \multirow[t]{3}{*}{$\mathrm{pH}$} & Initial & $7.16 \pm 0.14$ & $7.03 \pm 0.14$ & $0.034^{*}$ \\
\hline & Day-1 & $7.38 \pm 0.04$ & $7.15 \pm 0.14$ & $0.0001^{*}$ \\
\hline & pt & 0.0001 & 0.086 & \\
\hline \multirow[t]{3}{*}{$\mathrm{pCO}_{2}$} & Initial & $64.3 \pm 25.55$ & $78.25 \pm 32.67$ & $0.256^{*}$ \\
\hline & Day-1 & $41.72 \pm 6.03$ & $50.41 \pm 14.07$ & $0.043^{*}$ \\
\hline & pt & 0.002 & 0.035 & \\
\hline \multirow[t]{3}{*}{$\mathrm{paO}_{2}$} & Initial & $32.78 \pm 19.32$ & $46.23 \pm 16.96$ & $0.106^{*}$ \\
\hline & Day-1 & $99.31 \pm 32.07$ & $85.6 \pm 32.47$ & $0.336^{*}$ \\
\hline & pt & 0.0001 & 0.013 & \\
\hline \multirow[t]{3}{*}{$\mathrm{HCO}_{3}$} & Initial & $18.09 \pm 7.73$ & $15.3 \pm 6.01$ & $0.379^{*}$ \\
\hline & Day-1 & $21.82 \pm 5.12$ & $15.55 \pm 6.01$ & $0.014^{*}$ \\
\hline & pt & 0.007 & 0.924 & \\
\hline \multirow[t]{3}{*}{ Base excess } & Initial & $-5.8(-12-0.85)$ & $-8.65(-12.33-3.85)$ & $0.662 \ddagger$ \\
\hline & Day-1 & $-2.4(-6.25-2.175)$ & $-7.6(-12.38-1.425)$ & $0.158 \ddagger$ \\
\hline & $\mathrm{p} \ddagger$ & 0.009 & 0.889 & \\
\hline \multirow[t]{3}{*}{ Lactate } & Initial & $5.1(2.13-6.85)$ & $6.1(3.9-10.5)$ & $0.610 \ddagger$ \\
\hline & Day-1 & $1.8(1.3-2.25)$ & $4.5(2.93-9.6)$ & $0.002 \ddagger$ \\
\hline & $\mathrm{p} \ddagger$ & 0.002 & 0.441 & \\
\hline \multirow[t]{3}{*}{ WBC } & Initial & $13,170(5,480-16,480)$ & $23,805(14,387-52,440)$ & $0.029 \ddagger$ \\
\hline & Day-1 & $10,190(6,030-10,190)$ & $15,615(8,197-38,587)$ & $0.159 \ddagger$ \\
\hline & $\mathrm{p} \ddagger$ & 0.033 & 0.077 & \\
\hline \multirow[t]{3}{*}{ Hemoglobin } & Initial & $11 \pm 2.32$ & $9.78 \pm 2.34$ & $0.223^{*}$ \\
\hline & Day-1 & $9.9 \pm 1.82$ & $8.75 \pm 0.95$ & $0.106^{*}$ \\
\hline & $\mathrm{p}+$ & 0.077 & 0.146 & \\
\hline \multirow[t]{3}{*}{ Platelet count } & Initial & $136,000(57,000-294,000)$ & $137,000(74,500-386,000)$ & $0.958 \ddagger$ \\
\hline & Day-1 & $109,000(90,000-176,000)$ & $101,000(61,500-195,575)$ & $0.671 \ddagger$ \\
\hline & $\mathrm{p} \ddagger$ & 0.176 & 0.263 & \\
\hline \multirow[t]{3}{*}{ Urea } & Initial & $35(26.5-57.5)$ & $36.5(19.75-70.25)$ & $0.838 \ddagger$ \\
\hline & Day-1 & $32(11-62.5)$ & $26(14-93.25)$ & $0.884 \ddagger$ \\
\hline & $\mathrm{p} \ddagger$ & 0.420 & 0.999 & \\
\hline
\end{tabular}


Table IV. Continue.

\begin{tabular}{|c|c|c|c|c|}
\hline Parameters & & Survivors $(n=20)$ & Non-survivor $(\mathrm{n}=10)$ & $\mathrm{p}$ \\
\hline \multirow[t]{3}{*}{ Creatinine } & Initial & $0.7(0.38-0.86)$ & $0.98(0.72-1.20)$ & $0.047 \ddagger$ \\
\hline & Day-1 & $0.54(0.40-0.78)$ & $0.64(0.55-1.04)$ & $0.157 \ddagger$ \\
\hline & $\mathrm{p} \ddagger$ & 0.138 & 0.515 & \\
\hline \multirow[t]{3}{*}{ Albumin } & Initial & $2.78 \pm 0.78$ & $2.33 \pm 0.69$ & $0.175^{*}$ \\
\hline & Day-1 & $3.12 \pm 0.49$ & $2.48 \pm 0.64$ & $0.064^{*}$ \\
\hline & $\mathrm{p}+$ & 0.093 & 0.131 & \\
\hline \multirow[t]{3}{*}{ Chloride } & Initial & $103.89 \pm 4.84$ & $111.67 \pm 4.9$ & $0.001^{*}$ \\
\hline & Day-1 & $102.94 \pm 3.76$ & $112.67 \pm 6.42$ & $0.0001^{*}$ \\
\hline & $\mathrm{p}+$ & 0.148 & 0.412 & \\
\hline \multirow[t]{3}{*}{$\mathrm{LDH}$} & Initial & $716.5(462.75-2,293.75)$ & 317 (201-3,979.5) & $0.391 \ddagger$ \\
\hline & Day-1 & 710 (413-1,797) & $2,721(1,448-7,593)$ & $0.039 \ddagger$ \\
\hline & $\mathrm{p} \ddagger$ & 0.110 & 0.999 & \\
\hline
\end{tabular}

*Independent t-test (mean \pm SD), † Paired t-test, $\ddagger$ Mann-Whitney U test (median IQR), $\ddagger$ Wilcoxon test

ECMO: extracorporeal membrane oxygenation, $\mathrm{BP}$ : blood pressure $(\mathrm{mm} / \mathrm{Hg})$;

$\mathrm{pCO}_{2}$ : partial pressure of $\mathrm{CO}_{2}$ in the arterial blood $(\mathrm{mm} \mathrm{Hg}) ; \mathrm{paO}_{2}$ : partial pressure of oxygen in the arterial blood, platelet count $(\mathrm{K} / \mu \mathrm{l}), \mathrm{HCO}_{3}$ : bicarbonate $(\mathrm{mmol} / \mathrm{L})$, lactate $(\mathrm{mmol} / \mathrm{L}), \mathrm{WBC}$ : white blood cell count $(\mathrm{K} / \mu \mathrm{l})$, hemoglobin $(\mathrm{g} / \mathrm{dl})$, platelet count $(\mathrm{K} / \mu \mathrm{l})$; urea $(\mathrm{mg} / \mathrm{dl})$, creatinine $(\mathrm{mg} / \mathrm{dl})$, albumin $(\mathrm{g} / \mathrm{dl})$, chloride $(\mathrm{meq} / \mathrm{L})$, $\mathrm{LDH}$ : lactate dehydrogenase $(\mathrm{U} / \mathrm{L})$

\section{Discussion}

Mechanical circulatory support has been widely used in the treatment of cardiopulmonary failure in pediatric patients, and many recent studies have reported its outcomes.,4 However, many studies have been conducted to determine the indications and factors affecting mortality. ${ }^{5}$ The aim of this study was to report our experiences with pediatric critical patients placed on non-postcardiotomy ECMO in the PICU and to determine the variables associated with hospital mortality. We achieved an overall survival rate of $66.7 \%$ in our two and a half years' experience, which is comparable with that of the Extracorporeal Life Support Organization (ELSO) registry. ${ }^{6}$

In hypoxemic respiratory failure, ventilation with low tidal volume $(5-8 \mathrm{ml} / \mathrm{kg})$, alveolar recruitment with high PEEP, prone positioning and early initiation of neuromuscular blocking agents are recommended. Also, HFOV should be considered as an alternative ventilatory mode in hypoxic respiratory failure in patients in whom plateau airway pressures exceed $28 \mathrm{~cm} \mathrm{H}_{2} \mathrm{O}$ in the absence of clinical evidence of reduced chest wall compliance. However, in patients who do not benefit from these treatment approaches, hypoxemia may not improve and morbidity and mortality increase. ECMO support therapy is life-saving in patients with severe ARDS, refractory hypoxemia or hypercapnia.

In our study, hypoxemic respiratory failure was detected in 12 patients. The oxygenation index (OI) was $>16$ or the oxygenation saturation index (OSI) was $>12.3$ in all patients. High PEEP, lung recruitment maneuvers, prone position and neuromuscular blocking agent were used in all of these patients. In patients with pulmonary hypertension, inhaled nitric oxide was given. HFOV was used in clinically appropriate patients but ECMO supportive treatment was performed because the expected response could not be achieved and hypoxia could not be corrected. VV-ECMO was performed in 6 patients, and VA-ECMO was performed in 6 patients due to accompanying pulmonary HT, catecholamine need, and the effect on cardiac function. The survival rate was $83.3 \%$ in 12 patients who received ECMO due to hypoxemic respiratory failure. The survival rate of VV-ECMO was $66 \%$. Carpenter et al. ${ }^{7}$ jointly evaluated the pediatric and neonatal patients in their study, and VV-ECMO was performed for 83 patients, and 49 patients (59\%) survived. 
The most frequent indication was detected as pneumonia in patients who received VVECMO in this study. Kim et al. ${ }^{8}$ detected the most frequent indication as pneumonia in their study $(57.1 \%)$, and VV-ECMO was performed in 25 pediatric patients; the survival rate was found as $52 \%$.

Joffe et al. ${ }^{9}$ performed a review of 1,755 children with VA-ECMO and found that the cumulative survival after cardiac ECMO in children was 788/1755 (45\%). Thourani et al. ${ }^{10}$ reported an in-hospital survival rate of $88 \%$ in a group of cardiac ECMO patients with cardiomyopathy-myocarditis-arrhythmia, not related to congenital heart diseases (CHD). Kim et al. ${ }^{8}$ reported that the survival rate of patients without CHD was $56.5 \%$. Twenty-four patients received VA-ECMO in our study. The survival rate was $66.7 \%$, and the most frequent diagnosis was myocarditis in patients who had ECMO support due to cardiac indications. Patients with myocarditis had acute onset and short time before pediatric intensive care admission. Furthermore patients had no underlying additional disease. All these factors affect the prognosis positively. If we considered any sign of a lack of response to medical treatment, we decided to begin ECMO support. We think that high survival rates in patients with myocarditis are due to early ECMO indication and the short duration between indication and implementation of ECMO. CHD was detected in only 3 patients. (TAPVD in two patients, transposition of great arteries in one patient). The low number of patients with CHD who received ECMO was one of the factors that improved the results.

Laboratory values consistent with impaired kidney function are also common in patients on ECMO. For instance, markers associated with acute kidney injury such as $\mathrm{pH}$, lactate, creatinine levels are among parameters which distinguish outcomes. ${ }^{11-15}$ Our study has shown that laboratory values of kidney function precannulation $(\mathrm{pH}$, creatinine) and day- $1 \mathrm{pH}$, bicarbonate) are associated with poor outcomes similar to other studies. ${ }^{16}$ Moreover, our multivariate analysis indicated that $\mathrm{pH}$ was an independent predictor of mortality. Chloride, regulate the acid-base balance in the body, and the balance is organized by the kidneys. Chloride is a strong anion that provides the negative load in extracellular fluid and it has a significant role in the acid-base balance. It decreases the glomerular filtration rate and renin activity by performing renal vasoconstriction in patients with hyperchloremia. Hypo- and hyperchloremia were associated with poor results in critical patients. ${ }^{16-20}$ These results showed that kidney dysfunction contributed to mortality in critical pediatric patients. ${ }^{21}$

Urine output declines due to the renal perfusion decrease in the presence of low cardiac flow. The amount of extravascular and interstitial fluid increases, tissue oxygenation, and oxygen presentation to the lungs deteriorates. Blood lactate levels increase as a consequence of poor tissue perfusion in patients. ${ }^{12,22}$ Thus, the presence of low cardiac flow and kidney dysfunction result with increased morbidity and mortality.

In our study, metabolic acidosis before and during ECMO was a risk factor of mortality. Consistent with previous studies, pre-ECMO arterial $\mathrm{pH}$ was related to survival. ${ }^{23,24}$ Severe metabolic acidosis and low arterial $\mathrm{pH}$ indicate inadequate circulation, which could cause critical complications and death. ${ }^{24}$ Therefore, it is necessary to closely monitor the acid-base status of high-risk patients to decide upon early mechanical circulatory support insertion before irreversible organ damage occurs.

Sepsis remains a major cause of morbidity and mortality in children. The use of predictive and prognostic biomarkers has the potential to improve early recognition and timely intervention of patients with sepsis leading to improved outcomes. We showed that CRP and leucocyte were high in patients who were nonsurvivors. Leukocytosis and CRP are traditional inflammatory markers for the diagnosis of infection..$^{26,27}$ Leukocyte and CRP levels rise in response to infection and high levels have been 
found to correlate with the severity of infection, development of multiple organ dysfunction syndrome (MODS), and worse outcome in various studies. ${ }^{28,29}$

We evaluated the trends and predictive value of leukocytosis and CRP levels during treatment of pediatric patients on ECMO. We showed that leukocytosis and high CRP levels were effective factors in mortality, similar to other pediatric patient groups.

In addition, the patients who received ECMO support due to sepsis had the lowest survival. VA-ECMO was performed in 8 patients due to sepsis, and 6 patients died. Three patients who died as having bone marrow transplant, and they were immunosuppressed patients. Zabrocki et al. ${ }^{30}$ reported that children with sepsis who were supported with ECMO had a higher risk of mortality than those without sepsis, and Skinner et al. ${ }^{31}$ reported that children with sepsis who were on ECMO had an overall survival rate of $68 \%$. Also, immunosuppression is an accepted risk factor for ECMO-associated mortality. Grupta et al. ${ }^{32}$ reported that survival of immunocompromised children supported by ECMO was $31 \%$, which was significantly lower than that of non-immuncompromised children (57\%).

The ideal timing of ECMO for pediatric patients remains unclear. Steimer et al. ${ }^{33}$ reported that adult patients with acute respiratory distress syndrome (ARDS) who were cannulated within 48 hours of admission had an $80 \%$ survival rate at 90 days. Liao et al. ${ }^{34}$ showed that early establishment of ECMO might improve the prognosis for patients with refractory cardiogenic shock. Our study has shown that early ECMO initiation was associated with improved survival when compared with late ECMO.

In conclusion, this study's collective review of ECMO cases in our pediatric intensive care unit, shows an increasing trend in pediatric ECMO utilization. Although the number of patients is low, we present an acceptable survival rate, low complication rates, and reasonable shortterm neurologic outcomes in pediatric ECMO support. In addition, although early-initiated ECMO was demonstrated to improve the results, we argue that leukocytosis, low $\mathrm{pH}$, high CRP, high creatinine, and hyperchloremia at admission are the factors that negatively affect prognosis. Future studies are needed to identify risk factors and strategies to improve outcomes.

There were several limitations to this study. First, patient selection was limited because our study was a retrospective, observational, singlecenter study. Second, it is limited by the detail and completeness of the collected data. Thirdly, postop cardiac patients were not included in the study because they were followed up in a different intensive care unit. Therefore, the number of patients were limited with 30 patients.

\section{REFERENCES}

1. Baffes TG, Fridman JL, Bicoff JP, Whitehill JL. Extracorporeal circulation for support of palliative cardiac surgery in infants. Ann Thorac Surg 1970; 10: 354-363.

2. Bartlett RH, Gazzaniga AB, Huxtable RF, Schippers HC, O'Connor MJ, Jefferies MR. Extracorporeal circulation (ECMO) in neonatal respiratory failure. J Thorac Cardiovasc Surg 1977; 74: 826-833.

3. Fuchs A, Netz H. Ventricular assist devices in pediatrics. Images Paediatr Cardiol 2001; 3: 24-54.

4. Aharon AS, Drinkwater DC Jr, Churchwell KB, et al. Extracorporeal membrane oxygenation in children after repair of congenital cardiac lesions. Ann Thorac Surg 2001; 72: 2095-2101.

5. Alsoufi B, Al-Radi OO, Gruenwald C, et al. Extracorporeal life support following cardiac surgery in children: analysis of risk factors and survival in a single institution. Eur J Cardiothorac Surg 2009; 35: 1004-1011.

6. Barbaro RP, Paden ML, Guner YS, et al; on behalf of the ELSO member centers. Pediatric Extracorporeal Life Support Organization Registry International Report 2016. ASAIO J 2017; 63: 456-463.

7. Carpenter JL, Yu YR, Cass DL, et al. Use of venovenous ECMO for neonatal and pediatric ECMO: a decade of experience at a tertiary children's hospital. Pediatr Surg Int 2018; 34: 263-268. 
8. Kim H, Yang JH, Cho YH, Jun TG, Sung K, Han W. Outcomes of extracorporeal membrane oxygenation in children: an 11-year single-center experience in Korea. Korean J Thorac Cardiovasc Surg 2017; 50: 317-325.

9. Joffe AR, Leguier L, Robertson CM. Pediatric outcomes after extracorporeal membrane oxygenation for cardiac disease and for cardiac arrest: a review. ASAIO J 2012; 58: 297-310.

10. Thourani VH, Kirsbom PM, Kanter KR, et al. Venoarterial extracorporeal membrane oxygenation (VA-ECMO) in pediatric cardiac support. Ann Thorac Surg 2006; 82: 138-144.

11. Formica F, Avalli L, Colagrande L, et al. Extracorporeal membrane oxygenation to support adult patients with cardiac failure: predictive factors of 30-day mortality. Interact Cardiovasc Thorac Surg 2010; 10: 721-726.

12. Li CL, Wang H, Jia M, Ma N, Meng X, Hou XT. The early dynamic behavior of lactate is linked to mortality in postcardiotomy patients with extracorporeal membrane oxygenation support: a retrospective observational study. J Thorac Cardiovasc Surg 2015; 149: 1445-1450.

13. Combes A, Leprince P, Luyt CE, et al. Outcomes and long-term quality-of-life of patients supported by extracorporeal membrane oxygenation for refractory cardiogenic shock. Crit Care Med 2008; 36: 1404-1411.

14. Hsu PS, Chen JL, Hong GJ, et al. Extracorporeal membrane oxygenation for refractory cardiogenic shock after cardiac surgery: predictors of early mortality and outcome from 51 adult patients. Eur J Cardiothorac Surg 2010; 37: 328-333.

15. Doll N, Kiaii B, Borger M, et al. Five-year results of 219 consecutive patients treated with extracorporeal membrane oxygenation for refractory postoperative cardiogenic shock. Ann Thorac Surg 2004; 77: 151157.

16. Francischetti IMB, Szymanski J, Rodriguez D, Heo M, Wolgast LR. Laboratory and clinical predictors of 30- day survival for patients on extracorporeal membrane oxygenation (ECMO): 8-year experience at Albert Einstein College of Medicine, Montefiore Medical Center. J Crit Care 2017; 40: 136-144.

17. Yunos NM, Bellomo R, Story D, Kellum J. Bench-tobedside review: chloride in critical illness. Crit Care 2010; 14: 226.

18. Guidet B, Soni N, Della Rocca G, et al. A balanced view of balanced solutions. Crit Care 2010; 14: 325.

19. Soussi S, Ferry A, Chaussard M, Legrand M. Chloride toxicity in critically ill patients: what's the evidence? Anaesth Crit Care Pain Med 2016; 36: 125-130.
20. Tani M, Morimatsu H, Takatsu F, Morita K. The incidence and prognostic value of hypochloremia in critically ill patients. ScientificWorldJournal 2012; 2012: 474185.

21. Distelmaier K, Roth C, Binder C, et al. Urinary output predicts survival in patients undergoing extracorporeal membrane oxygenation following cardiovascular surgery. Crit Care Med 2016; 44: 531538.

22. Loforte A, Marinelli G, Musumeci F, et al. Extracorporeal membrane oxygenation support in refractory cardiogenic shock: treatment strategies and analysis of risk factors. Artif Organs 2014; 38: E129-E141.

23. Kumar TK, Zurakowski D, Dalton $\mathrm{H}$, et al. Extracorporeal membrane oxygenation in postcardiotomy patients: factors influencing outcome. J Thorac Cardiovasc Surg 2010; 140: 330336.e2.

24. Chow G, Koirala B, Armstrong D, et al. Predictors of mortality and neurological morbidity in children undergoing extracorporeal life support for cardiac disease. Eur J Cardiothorac Surg 2004; 26: 38-43.

25. Cengiz P, Seidel K, Rycus PT, Brogan TV, Roberts JS. Central nervous system complications during pediatric extracorporeal life support: incidence and risk factors. Crit Care Med 2005; 33: 2817-2824.

26. Nunez Lopez O, Cambiaso-Daniel J, Branski LK, Norbury WB, Herndon DN. Predicting and managing sepsis in burn patients: current perspectives. Ther Clin Risk Manag 2017; 13: 11071117.

27. Wacker C, Prkno A, Brunkhorst FM, Schlattmann P. Procalcitonin as a diagnostic marker for sepsis: a systematic review and meta-analysis. Lancet Infect Dis 2013; 13: 426-435.

28. Wang C, Gao L, Zhang ZG, et al. Procalcitonin is a stronger predictor of long-term functional outcome and mortality than high-sensitivity C-reactive protein in patients with ischemic stroke. Mol Neurobiol 2016; 53: 1509-1517.

29. Siddigui I, Jafri L, Abbas Q, Reheem A, Haque A. Relationship of serum procalcitonin, C-reactive protein, and lactic acid to organ failure and outcome in critically ill pediatric population. Indian J Crit Care Med 2018; 22: 91-95.

30. Zabrocki LA, Brogan TV, Statler KD, Poss WB, Rollins MD, Bratton SL. Extracorporeal membrane oxygenation for pediatric respiraty failure: survival and predictors of mortality. Crit Care Med 2011; 39: 364-370. 
31. Skinner SC, Iocono JA, Ballard $\mathrm{HO}$, et al. Improved survival in venovenous vs venoarterial extracorporeal membrane oxygenation for pediatric noncardiac sepsis patients: a study of the Extracorporeal Life Support Organization Registry. J Pediatr Surg 2012; 47: 63-67.

32. Gupta M, Shanley TP, Moler FW. Extracorporeal life support for severe respiratory failure in children with immune compromised conditions. Pediatr Crit Care Med 2008; 9: 380-385.
33. Steimer DA, Hernandez O, Mason DP, Schwartz GS. Timing of ECMO initiation impacts survival in influenza-associated ARDS. Thorac Cardiovasc Surg 2019; 67: 212-215.

34. Liao XZ, Zhou ZB, Cheng Z, et al. The prognostic risk factors of ECMO in patients with cardiogenic shock: a retrospective cohort analysis. Heart Surg Forum 2017; 20: E170-E177. 